\title{
A Xeno-free Media for the In Vitro Expansion of Human Spermatogonial Stem Cells
}

\author{
Meghan Robinson ${ }^{\mathrm{a}}$, Luke Witherspoon, ${ }^{\mathrm{a}, \mathrm{b}, \mathrm{c}}$, Stephanie Willerth ${ }^{\mathrm{d}-\mathrm{f}}$, \\ Ryan Flannigan ${ }^{\mathrm{a}, \mathrm{b}, \mathrm{g}}$
}

\begin{abstract}
a) Vancouver Prostate Centre, 2660 Oak St, Vancouver, British Columbia, Canada V6H $3 Z 6$
b) Department of Urologic Sciences, University of British Columbia, 2329 West Mall, Vancouver, British Columbia, Canada V6T 1 Z4

c) Department of Urology, The Ottawa Hospital, 501 Smyth Rd, Ottawa, Ontario, Canada K1H 8L6

d) Division of Medical Sciences, University of Victoria, 3800 Finnerty Road, Victoria, British Columbia, Canada V8P 5C2

e) Department of Mechanical Engineering, University of Victoria, Victoria, British Columbia, Canada

f) School of Biomedical Engineering, University of British Columbia, 2329 West Mall, Vancouver, British Columbia, Canada V6T 1Z4

g) Department of Urology, Weill Cornell Medicine, 1300 York Ave, New York, New York 10065, United States
\end{abstract}

\section{CORRESPONDING AUTHOR}

Ryan Flannigan, MD

Department of Urologic Sciences, University of British Columbia, Vancouver, British Columbia Gordon \& Leslie Diamond Health Care Centre

Level 6, 2775 Laurel Street

Vancouver, BC Canada V5Z 1M9

Email: ryan.flannigan@ubc.ca 


\section{ABSTRACT}

In vitro expansion of spermatogonial stem cells (SSCs) has been established using animal-derived fetal bovine serum (FBS) and bovine serum albumin (BSA). However, the use of animal components during cell culture introduces the risk of contaminating cells with pathogens, and leads to animal epitope expression, rendering them unsuitable for medical use. Therefore, this study set out to develop a xeno-free, fully defined media for the expansion of human SSCs. We show that the molecules Prostaglandin D2 (PGD-2) and Insulin-Like Growth Factor 1 (IGF-1) can replace FBS and BSA in cell culture media without loss of viability or expansion capability, and that RhoAssociated, Coiled-Coil Containing Protein Kinase (ROCK) inhibitor Y-27632 supplementation improves viability after cryopreservation. Long-term SSC cultures expanded in xeno-free, defined culture conditions shared identical protein expression profiles for well-known SSC markers, while gene expression analyses revealed a significant improvement in quiescent SSC and pan-germ markers. This xeno-free, defined formulation allows for standardized SSC culture free of animal pathogens.

\section{KEYWORDS}

Adult Germline Stem Cells, Cell Culture Techniques, Humans, Insulin-Like Growth Factor 1, Prostaglandins 


\subsection{INTRODUCTION ${ }^{1}$}

Oncological therapies involving radiation and chemotherapy can be severely detrimental to male fertility, with fertility preservation becoming increasingly highlighted as a key component of cancer survivorship programs.[1] However, many patients undergoing cancer therapies are unable to access the traditional methods of fertility preservation. This is certainly true in the pre-pubertal pediatric population where sperm banking is not possible and cryopreservation of testis tissue remains in the experimental phases of use.[2, 3] Although xenotransplantation of spermatogonial stem cells (SSCs) and testis tissue has been explored, success has been limited, and concerns about possible retrovirus transmission remain.[4-7] In vitro systems for restoring spermatogenesis have proven successful using neonatal mice testicular tissues, $[8,9]$ but have yet to be optimized for human testicular tissues due to a lack of available tissue for research.[10] Orthotopic autotransplantation of SSCs and testicular tissue in animal models have shown promise, with complete recovery of spermatogenesis, but methods to exclude the risk of re-introducing cancer cells are needed.[10-12] SSCs may represent the most promising therapeutic avenue, ultimately allowing autologous transplantation, or even in vitro spermatogenesis.[10, 13] SSCs have been successfully isolated from prepubertal testicular tissues,[14] and shown to expand and maintain a stable epigenetic profile in vitro.[15] Furthermore, SSC autologous transplantation studies using

\footnotetext{
${ }^{1}$ ACTA2: actin alpha 2, smooth muscle, BSA:bovine serum albumin, CREB:Clinical Research Ethics Boards, DAZL:deleted in azoospermia like, DDX4 -= DEAD-box helicase 4, EGF:epidermal growth factor, FBS:fetal bovine serum, FGF2:fibroblast growth factor 2, FGFR3:fibroblast growth factor receptor 3, GDNF:glial cell derived neurotrophic factor, GFRA1:GDNF family receptor alpha 1, GPR125:G protein-coupled receptor 125, hiPSC:human induced pluripotent stem cell, hPL:human platelet lysate, ID4:inhibitor of DNA binding 4, HLH protein, IGF-1:insulin-like growth factor 1, LIF:leukemia inhibitory factor, MEF:mouse embryonic feeder, OCT4:octamer binding protein 4, PGD-2:prostaglandin D2, PRM1:protamine 1, ROCK:Rho-Associated, CoiledCoil Containing Protein Kinase, SOX9:SRY-box transcription factor 9, SSC:spermatogonial stem cell, SSEA4:stage specific embryonic antigen 4, STRA8:stimulated by retinoic acid 8, SYCP3:synaptonemal complex protein 3, THY1/CD90:Thy-1 Cell Surface Antigen, UTF1:undifferentiated embryonic cell transcription factor 1
} 
irradiated macaques rendered infertile by alkylating or irradiating chemotherapy showed that they are capable of restoring spermatogenesis.[10, 16, 17] While re-introducing cancer cells remains a risk with SSC autologous transplantation, culture methods and sorting strategies are being actively investigated to remove contaminating cancer cells from SSC cultures,[13] and in one promising pilot study, co-culture of acute lymphoblastic leukemia cells with SSCs for two weeks was found to eliminate cancer cells from three different cancer patients as evidenced by highly sensitive polymerase chain reaction to identify the presence of leukemic cells.[18]

A critical step towards adoption of SSC transplantation to restore fertility is refinement of the in vitro expansion process.[10, 19] It is estimated that SSC populations will require a several hundred fold increase to achieve adequate transplantation cell volumes,[14] making appropriate cell culture techniques an avenue that must be explored to ensure safe culture conditions. Current cell culture techniques often rely heavily on animal derived additives to help drive cell population expansion and growth.[20] However, this long-standing approach is coming under increased scrutiny given that animal derived growth factors may alter typical cell gene and protein expression from that found in normal physiological in vivo conditions,[21] even causing expression of animal epitopes,[22] while variation between batches of animal derived growth factors limits the standardization of cell culture protocols. $[23,24]$ Furthermore, concerns exist as to the possibility of animal derived antigens and infectious agents that could be transmitted into a human, should in vitro expanded cells be transplanted back into human beings.[25-28] Limited research has gone into the production of animal serum free media to help address this issue, with most work focused on mesenchymal derived stem cells and pluripotent stem cells.[29-31] Currently, standard SSC expansion media is composed of Stempro34 ${ }^{\mathrm{TM}}$ SFM, a Food and Drug Administration (FDA)approved xeno-free, defined basal media[32], supplemented with additional additives including 
the undefined animal-derived components fetal bovine serum (FBS) and bovine serum albumin (BSA).[14, 33, 34] We show that the addition of the spermatogenic growth factors Insulin-Like Growth Factor-1 (IGF-1), an SSC proliferation regulator,[35] and Prostaglandin D2 (PGD-2), an SSC quiescence regulator,[36-38] can replace the animal serum components in this formulation to enable xeno-free in vitro expansion of SSCs, as a step towards translation to clinical use. This study provides a novel protocol for xeno-free expansion of SSCs, and presents comparative phenotype analyses using reverse transcription quantitative polymerase chain reaction (RT-qPCR) and immunocytochemistry analyses of primary SSCs expanded using a xeno-free, chemically defined media versus standard animal serum-supplemented media.

\subsection{METHODS}

\subsection{Ethical Approval}

Testis biopsy samples were obtained through the University of British Columbia Andrology

Biobank, with informed consent for research (CREB approved protocol H18-03543). Experiments using hiPSCs in this study were not subject to ethics approval from the University of British Columbia Clinical Research Ethics Boards or Stem Cell Oversight Committee, since they were derived from somatic cells and not intended for transfer into humans or non-human animals.

\subsection{Human induced pluripotent stem cell (hiPSC) culture}

The hiPSC line used was the 1-DL-01 line from WiCell.[39] hiPSCs were expanded on Growth Factor Reduced Matrigel (Corning, 354230) in mTeSR TM-Plus medium (STEMCELL Technologies, $100-0276$ ), at $37^{\circ} \mathrm{C}$ and $5 \% \mathrm{CO}_{2}$, and passaged when $90 \%$ confluent using ReLeSR ${ }^{\mathrm{TM}}$ enzyme-free selective passaging reagent (STEMCELL Technologies, 05872) to maintain purity. 


\subsection{Differentiation of SSCs from hiPSCs (hSSCs)}

hSSCs were differentiated from hiPSCs as previously described,[40] with a magnetic activated cell sorting (MACS) step to purify for Thy-1 Cell Surface Antigen (THY1/CD90)- expressing cells. hiPSCs were grown on Matrigel in Minimum Essential Medium Alpha ( $\alpha$ MEM, Gibco A10490-01), 1X GlutaMAX (Thermofisher, 35050079), 1X Insulin Transferrin Selenium Liquid Media Supplement (ITS, Millipore Sigma, I13146), 0.2\% BSA (Miltenyi Biotec, 130-091-376), 1\% penicillin/streptomycin (Sigma Aldrich, P4333), $1 \mathrm{ng} / \mathrm{mL}$ human recombinant Fibroblast Growth Factor 2 (FGF2, STEMCELL Technologies, 78003.1), $20 \mathrm{ng} / \mathrm{mL}$ animal component-free human recombinant Glial Cell Derived Neurotrophic Factor (GDNF, STEMCELL Technologies, 78139), 0.2\% Chemically Defined Lipid Concentrate (Thermofisher, 11905031), and $200 \mu \mathrm{g} / \mathrm{mL}$ L-ascorbic acid (Sigma, A4544). Medium was changed every 2 days for 12-15 days and cells were grown at $37^{\circ} \mathrm{C}$ and $5 \% \mathrm{CO}_{2}$. Cells were then switched to expansion medium as previously described,[33] composed of StemPro-34TM SFM (Thermofisher, 10639011) supplemented with 1X ITS, $30 \mu \mathrm{g} / \mathrm{ml}$ sodium pyruvate (Sigma, S8636), $1 \mu \mathrm{l} / \mathrm{mL}$ sodium DL-lactic acid solution (Sigma, L4263), 5 mg/ml BSA, 1\% FBS (Gibco, 12483-020), 1X GlutaMAX, $5 \times 10^{-5}$ M 2mercaptoethanol (Gibco, 31350-010), 1X Minimal Essential Medium (MEM) Vitamin Solution (Gibco, 11120052), 10 $0^{-4} \mathrm{M}$ L-ascorbic acid, $10 \mu \mathrm{g} / \mathrm{ml}$ biotin (Sigma, B4639), $30 \mathrm{ng} / \mathrm{ml} \beta$-estradiol (Sigma, E2758), $60 \mathrm{ng} / \mathrm{ml}$ progesterone (Sigma, P8783), $20 \mathrm{ng} / \mathrm{mL}$ human recombinant Epidermal Growth Factor (EGF, STEMCELL Technologies, 78006.1), $10 \mathrm{ng} / \mathrm{mL}$ human recombinant Leukemia Inhibitory Factor (LIF, STEMCELL Technologies, 78055.1), and 10 ng/mL GDNF. hSSCs were passaged onto CellAdhere ${ }^{\mathrm{TM}}$ Laminin-521 coated plates (STEMCELL Technologies, 77004) using TrypLE ${ }^{\mathrm{TM}}$ Express Enzyme (Thermofisher, 12604013). 12 million cells were purified for $\mathrm{CD}^{+} 0^{+}$cells using a PE-conjugated antibody for anti-CD90 (R\&D Systems, 
FAB2067P), the EasySep ${ }^{\text {TM }}$ Human PE Positive Selection Kit II (STEMCELL Technologies, 17664), and EasySep ${ }^{\mathrm{TM}}$ Magnet (STEMCELL Technologies, 18000).

\subsection{Primary SSC isolation and culture}

Primary testicular cells were isolated from human testicular biopsies as previously described.[41]

Testicular biopsies were transported to the lab on ice in Hypothermosol ${ }^{\circledR}$ FRS (STEMCELL Technologies, 07935) and processed within 1-2 hours. They were rinsed three times with Hank's Balanced Salt Solution (HBSS, Millipore Sigma, 55021C), cut into $1 \mathrm{~mm}^{3}$ pieces with surgical scissors, and digested by Collagenase NB4 (Nordmark Biochemicals, S1745402) at 2 PZU / 100 mg tissue, for 5 minutes at $37^{\circ} \mathrm{C}$ and $250 \mathrm{rpm}$. The sample was vigorously shaken and incubated for a further 3 minutes at $37^{\circ} \mathrm{C}$ and $250 \mathrm{rpm}$. After spinning for 5 minutes at $200 \mathrm{x} \mathrm{g}$, sedimented tubules were rinsed 3 times with HBSS, with spinning at $200 \mathrm{x} g$ for 5 minutes in between each rinse. The sedimented tubules were re-suspended in $0.25 \%$ Trypsin/EDTA (Sigma, T3924) with $0.8 \mathrm{kU} / 100 \mathrm{mg}$ DNase I (Sigma, D4263), and pipetted 3-5 times with a $5 \mathrm{~mL}$ pipette followed by incubation for 5 minutes at $37^{\circ} \mathrm{C}$. This process of pipetting followed by incubation was repeated for a total of 3 incubations. FBS was added to stop the digestion at a final concentration of 10\%, and the tubules were filtered through a $70 \mu \mathrm{m}$ filter, followed by a $40 \mu \mathrm{m}$ filter, and centrifuged for 15 minutes at $600 \mathrm{x}$ g. The cells were then sorted into somatic and germ fractions by overnight plating in a single well of a tissue culture-treated 6-well plate in media as described for hSSC culture. Non-adherent cells (germ cells) were transferred the next day to a single well of a CellAdhere ${ }^{\mathrm{TM}}$ laminin 521-coated 6-well plate, and expanded in the same media at $37^{\circ} \mathrm{C}$ and $5 \%$ $\mathrm{CO}_{2}$.

\subsection{Experimental conditions for xeno-free expansion}

hSSCs were used in place of primary SSCs for preliminary experiments to minimize the loss of human primary SSCs, which are not often available for research. Human recombinant IGF-1 
(Peprotech, 100-11) and the small molecule PGD-2 (Peprotech, 4150768) were added to cultures of hiPSC-derived SSCs in SSC expansion media without BSA and FBS, separately or in combination, at $10 \mathrm{ng} / \mathrm{mL}$ each. The concentration was chosen to match that of the other growth factors LIF, GDNF and FGF-2 already present in the expansion media. Cell viability and expandability was assessed over the course of a single passage grown at $37^{\circ} \mathrm{C}$ and $5 \% \mathrm{CO}_{2}$ and compared to a control group in the standard media. Viability was also assessed after cryopreservation and thawing, with or without $10 \mathrm{ng} / \mathrm{mL}$ ROCK inhibitor Y-27632 (STEMCELL Technologies, 72302). The condition which promoted the best viability and propagation was then applied to primary SSC cultures for 3 passages at $37^{\circ} \mathrm{C}$ and $5 \% \mathrm{CO}_{2}$ and 2 freeze-thaw cycles. Cells were cryopreserved in serum-free, chemically defined CryoStor ${ }^{\mathrm{TM}}$ CS10 (STEMCELL Technologies, 07930), placed in a Mr. Frosty ${ }^{\mathrm{TM}}$ (Nalgene) cooling container at $-80^{\circ} \mathrm{C}$ for 24 hours, followed by transfer to liquid nitrogen. Cells were imaged using an EVOS XL Core imaging System (Invitrogen), and images were processed with ImageJ open source software.

\subsection{Immunocytochemistry}

Cells were fixed for 15 minutes in 4\% paraformaldehyde solution (PFA, Thermo Scientific, J19943-K2), permeabilized for 15 minutes in 0.1\% Triton X-100 (Sigma, X100) in phosphate buffered saline (PBS), and blocked for 2 hours in 5\% normal goat serum (NGS, Abcam, ab7481) in PBS. Primary antibodies were diluted in PBS as follows: anti-Octamer-Binding Protein 4 (OCT4, Abcam, ab184665) 1:500, anti-SRY-Box Transcription Factor 9 (SOX9, Abcam, ab76997) 1:500, anti-Thy-1 Cell Surface Antigen (THY1/CD90, Abcam, ab133350) 1:200, antiGDNF Family Receptor Alpha 1 (GFRA1, Abcam, ab84106) 1:200, anti-Stage-Specific Embryonic Antigen-4 (SSEA4, Abcam ab16287) 1:300, anti-G Protein-Coupled Receptor 125 (GPR125, Abcam, ab51705) 1:200, anti-Actin Alpha 2, Smooth Muscle (ACTA2, Thermofisher, 14-9760-82) 1:500, and incubated overnight at $4^{\circ} \mathrm{C}$ in the dark. Cells were rinsed 3 times with PBS 
for 15 minutes each at $4^{\circ} \mathrm{C}$ in the dark. Goat anti-Rabbit IgG $(\mathrm{H}+\mathrm{L})$ Highly Cross-Adsorbed Secondary Antibody Alexa Fluor 488 (Thermofisher, A-11034) or Goat anti-Mouse IgG (H+L) Highly Cross-Adsorbed Secondary Antibody Alexa Fluor 568 (Thermofisher, A-11031) were diluted 1:200 in PBS and incubated with the cells for 4 hours at $4^{\circ} \mathrm{C}$ in the dark. Cells were rinsed another 3 times with PBS for 15 minutes each at $4^{\circ} \mathrm{C}$ in the dark. 4',6-diamidino-2-phenylindole (DAPI, Abcam, ab228549) was diluted to $2.5 \mu \mathrm{M}$ in PBS and added to the cells for 15 minutes in the dark at room temperature, and replaced by PBS. Cells were imaged using a Zeiss AXio Observer microscope equipped with laser excitation and fluorescence filters for AlexaFluor 488, AlexaFluor 568 and DAPI, and images were processed using ZEN Blue and ImageJ open source software.

\subsection{Reverse Transcription Qualitative Polymerase Chain Reaction (RT-qPCR)}

RNA was extracted using an RNeasy Plus Micro Kit (Qiagen, 74034), and checked for integrity using an Agilent 2200 Tapestation System with High Sensitivity RNA Screentape (Agilent, 50675579), High Sensitivity RNA ScreenTape Sample Buffer (Agilent, 5067- 5580), and High Sensitivity RNA ScreenTape Ladder (Agilent, 5067- 5581). cDNA was generated using iScript ${ }^{\mathrm{TM}}$ Reverse Transcription Supermix (Bio-Rad, 1708840) with a Tetrad2 Peltier Thermal Cycler (BioRad). RT-qPCR was done with SsoAdvanced ${ }^{\mathrm{TM}}$ Universal SYBR ${ }^{\circledR}$ Green Supermix (BioRad, 1725270) on a LightCycler96 (Roche). Primers used were PrimePCR ${ }^{\text {TM }}$ SYBR $®$ Green Assays as listed in Table 1. Technical replicates were carried out in triplicate. Analyses was done in Excel and GraphPad Prism Software. Ct values were normalized to Glyceraldehyde-3-Phosphate Dehydrogenase (GAPDH). Technical replicate outliers were detected using Grubbs' Test, with $\alpha=0.05$. The $3^{\text {rd }}$ control biological replicate was excluded as an outlier. Results of RT-qPCR are presented as the average Relative Quantification $\left(\mathrm{RQ}=2^{-\Delta \Delta \mathrm{Ct}}\right)$ values and standard deviations of the 
biological replicates. Any undetected samples were given a $\mathrm{Ct}$ value of the maximum detected cycles plus 1 .

\begin{tabular}{|c|c|c|}
\hline Gene & Amplicon Content Sequence & $\begin{array}{l}\text { Bio-Rad Unique } \\
\text { Assay ID }\end{array}$ \\
\hline DAZL & $\begin{array}{l}\text { GAACATACTGAGTTATAGGATTCATCGTGGTTGTGGGCTGCATATAAGTTTCAGT } \\
\text { GTTTGGATTAGTCCAGACATTCTGAAACTGTGGTGGAGGAGGATGATTAAAAACC } \\
\text { AAAGGACGTGG }\end{array}$ & qHsaCED0042658 \\
\hline DDX4 & $\begin{array}{l}\text { TATTCTGGAGAAAATGGAGACAATTTTAACAGGACTCCAGCTTCATCATCAGAAA } \\
\text { TGGATGATGGACCTTCTCGAAGAGATCATTTCATGAAAAGTGGATTTGCCTCTGG } \\
\text { GCGGAATTTTGGAAACAGAGATGCTGGTGAGTGTAATAAGCGAGATAATACATC } \\
\text { CAC }\end{array}$ & qHsaCID0008844 \\
\hline FGFR3 & $\begin{array}{l}\text { TTTATTGAGTTTTTACAAGATGTATTTGTTGTAGACTTAACACTTCTTACGCAATGC } \\
\text { TTCTAGAGTTTTATAGCCTGGACTGCTACCTTTCAAAGCTTGGAGGGAAGCCG }\end{array}$ & qHsaCED0042267 \\
\hline GAPDH & $\begin{array}{l}\text { GTATGACAACGAATTTGGCTACAGCAACAGGGTGGTGGACCTCATGGCCCACAT } \\
\text { GGCCTCCAAGGAGTAAGACCCCTGGACCACCAGCCCCAGCAAGAGCACAAGAG } \\
\text { GAAGAGAGAGACCCTCACTGCTGGGGAGTCCCTGCCACAC }\end{array}$ & qHsaCED0038674 \\
\hline ID4 & $\begin{array}{l}\text { GTTTTGCCCAGTATAGACTCGGAAGTAACAGTTATAGCTAGTGGTCTTGCATGAT } \\
\text { TGCATGAGATGTTTAATCACAAATTAAACTTGTTCTGAGTCCATTCAAATGTGTTT } \\
\text { TTTTAAATGTAGATT }\end{array}$ & qHsaCED0046882 \\
\hline UTF1 & $\begin{array}{l}\text { GCCGCCGCCGCTACAAGTTCCTTAAAGACAAGTTTCGCGAGGCGCACGGCCAG } \\
\text { CCGCCCGGGCCCTTCGACGAGCAGATCCGGAAGCTCATG }\end{array}$ & qHsaCED0046843 \\
\hline \multicolumn{3}{|c|}{$\begin{array}{l}\text { Abbreviations: DAZL = Deleted in Azoospermia-Like, DDX4 = DEAD-Box Helicase 4, DMRT1 = } \\
\text { Doublesex And Mab-3 Related Transcription Factor 1, FGFR3 = Fibroblast Growth Factor Receptor } \\
\text { 3, GAPDH = Glyceraldehyde-3-Phosphate Dehydrogenase , ID4 = Inhibitor Of DNA Binding } 4 \text { HLH } \\
\text { Protein, PRM1 = Protamine 1, STRA8 = Stimulated by Retinoic Acid 8, SYCP3 = Synaptonemal } \\
\text { Complex Protein 3, UTF1 = Undifferentiated Embryonic Cell Transcription Factor } 1 .\end{array}$} \\
\hline
\end{tabular}

Table 1. Amplicon content sequences (amplicon sequence with additional base pairs added to the beginning and/or end of the sequence), and Unique Assay IDs for Bio-Rad PrimePCR ${ }^{\mathrm{TM}}$ primer pairs used for RT-qPCR. 


\subsection{Statistics}

Statistics were performed using GraphPad Prism software. Each experiment was performed in biological triplicate. Significance between groups was determined by comparing $\Delta \mathrm{Ct}$ values using a student's unpaired two-tailed t-test, with $\alpha=0.05$.

See KRT for further information on the essential materials and resources described above.

\subsection{RESULTS}

Because of the rare availability of human testicular tissue for research, we derived SSCs from hiPSCs (hSSCs) for preliminary experimentation of the xeno-free media formulation, before experimenting on primary SSCs over long-term cultures.

\subsection{Characterization of hSSCs and primary SSCs}

After expanding isolated primary SSCs (Figure 1A) and differentiated hSSCs (Figure 1B), we validated their phenotypes by immunocytochemistry. Undifferentiated hiPSCs showed positive immunoreactivity for the pluripotency marker OCT4 as expected, while hSSCs were negative, confirming a loss of pluripotency (Figure 1C). hSSCs were also positive for the well-known SSC markers GPR125, GFRA1, CD90/THY1, and SSEA4, confirming their successful adoption of an SSC-like phenotype (Figure 1C). Likewise, primary SSCs showed positive immunoreactivity for GPR125, GFRA1, CD90 and SSEA4, and were negative for the testicular somatic cell markers ACTA2 and SOX9, confirming there was no contamination with somatic cell types (Figure 1D). 


\section{A ISOLATION OF PRIMARY GERM CELLS}

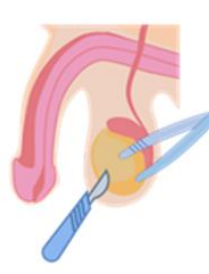

TESE biopsy

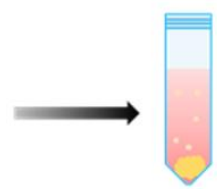

Digestion into single cells
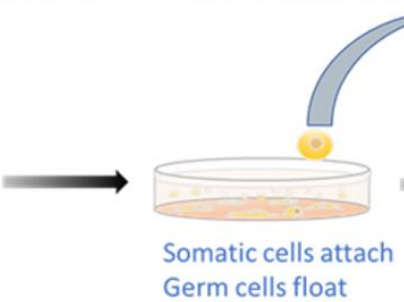

Separate adherent somatic cells and non-adherent germ cells
Collect and plate nonadherent germ cells on laminin-coated plates

\section{B DIFFERENTIATION OF SSCS FROM HIPSCS}

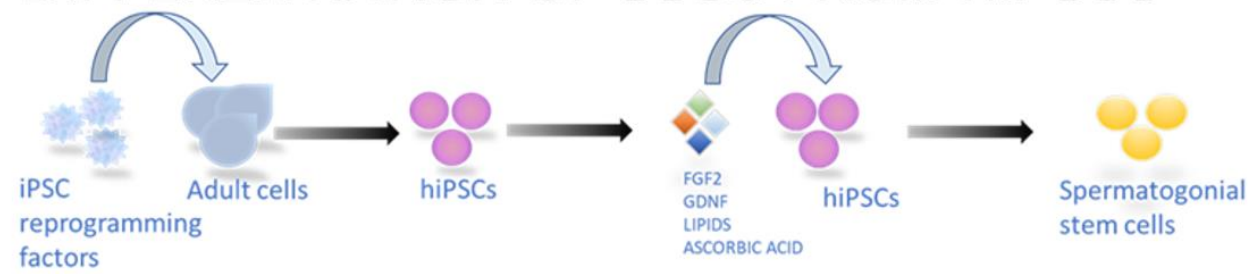

Reprogram adult cells into hiPSCs

Treat hiPSCs with factors to derive spermatogonial stem cells

\section{HIPSC-DERIVED SSC CHARACTERIZATION}

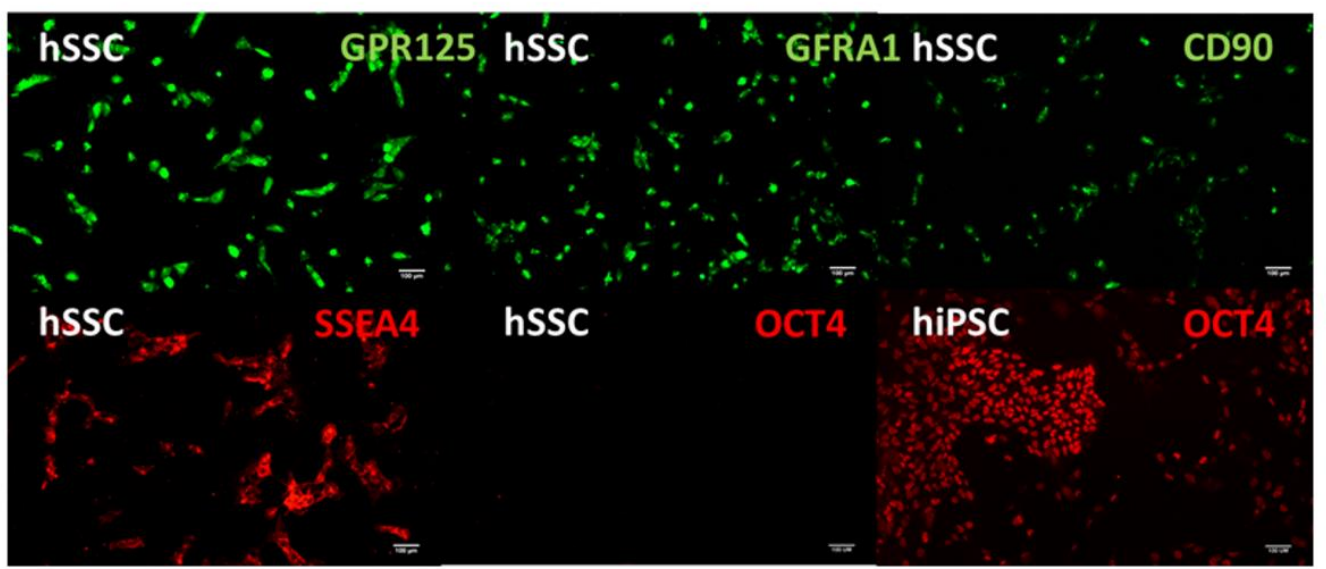

D PRIMARY SSC CHARACTERIZATION

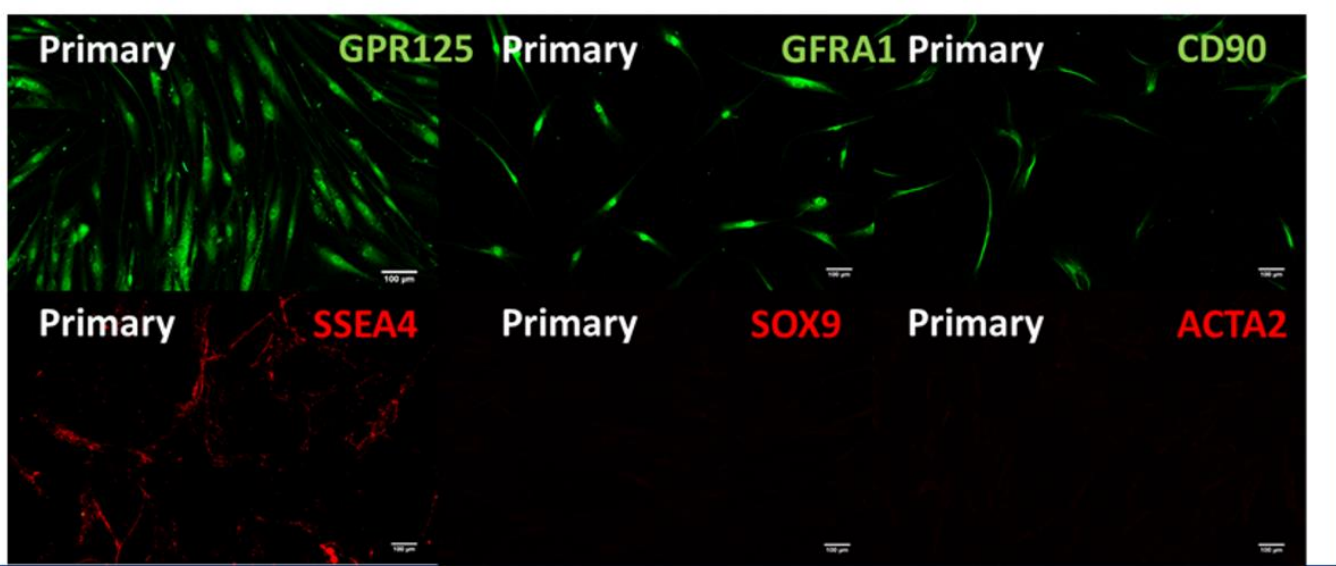


Figure 1: Isolation/derivation and characterization of primary SSCs and hSSCs. A) Schematic representing primary SSC isolation: Testicular Sperm Extraction (TESE) biopsies were dissociated into single cells, plated on tissue culture plates, and then 24 hours later the non-adherent germ cells were collected and plated on laminin-coated plates. B) Schematic representing SSC derivation from hiPSCs: hiPSCs are reprogrammed from adult fibroblasts and then cultured with FGF2, GDNF, lipids, and ascorbic acid to promote SSC differentiation. C) hSSC expression of SSC markers GPR125, GFRA1, CD90 and SSEA4, and the pluripotency factor OCT4, and hiPSC expression of OCT4. D) Primary SSC expression of the SSC markers GPR125, GFRA1, CD90 and SSEA4, and the testicular somatic markers ACTA2 and SOX9. All scale bars are $100 \mu$ m. Abbrevations: FGF2 = Fibroblast Growth Factor 2, GDNF = Glial Cell-Derived Neurotrophic Factor, GPR125 = G-Protein Coupled Receptor 125, GFRA1 = GDNF Family Receptor Alpha 1, CD90 = Thy-1 Cell Surface Antigen, SSEA4 = Stage-Specific Embryonic Antigen 4, OCT4 = Octamer Binding Protein 4, ACTA2 $=$ Actin Alpha 2, Smooth Muscle, SOX9 = SRY=Box Transcription Factor 9, hiPSC = human induced pluripotent stem cell, SSC = spermatogonial stem cell, hSSC = human induced pluripotent stem cellderived spermatogonial stem cell, Primary $=$ primary spermatogonial stem cell, TESE $=$ testicular sperm extraction.

\subsection{Establishment of xeno-free media}

Removal of the animal components FBS and BSA from standard SSC expansion media induced cell death, therefore we experimented with the supplementation of two spermatogenic factors: IGF-1 and PGD-2 (Figure 2A).[35, 36] We found that the addition of both was sufficient to rescue the cells (Figure 2C). Furthermore, these factors promoted viability and growth of the hSSCs over several passages on par with the standard media condition (Figure 2B). Interestingly, IGF-1 or PGD-2 alone could not rescue the cells (Figure 2C). 


\section{A Schematic}

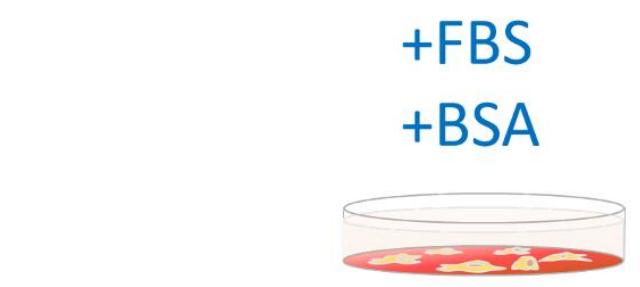

B Standard conditions

+ FBS

$+\mathrm{BSA}$

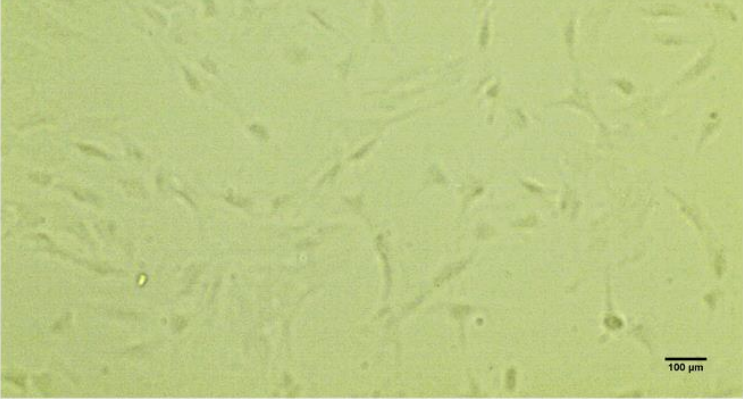

C Xeno-free conditions

-FBS

$\triangle I G F-1$

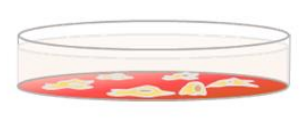

conditions

-BSA

+ PGD-2

$=$

+IGF-1

$+P G D-2$

Figure 2: Survival of hSSCs in xeno-free media conditions. A) Schematic representing the experimental culture conditions: the standard conditions included FBS and BSA supplementation, while the experimental xeno-free conditions had removed FBS and BSA and additional supplementation of PGD-2 and IGF-1. B) Microscope image of the hSSCs in standard conditions. C) Microscope images of the hSSCs in the experimental xeno-free media without IGF-1 or PGD-2, with IGF-1 or PGD-2, and with both IGF-1 and PGD-2. All scale bars are $100 \mu \mathrm{m}$. Abbreviations: $\mathrm{hSSC}=$ human induced pluripotent stem cell-derived spermatogonial stem cell, FBS = fetal bovine serum, BSA = bovine serum albumin, PGD-2 = prostaglandin D2, IGF-1 = Insulin-Like Factor 1. 
Cryopreserved hSSCs were not viable upon thawing in the xeno-free media formulation, but could be rescued by the one-time addition of the apoptosis inhibitor Y-27632[42] during seeding (Figure 3B), and remained viable and expandable thereafter.

\subsection{Comparison of primary SSCs phenotypes in xeno-free media compared to standard media}

Human primary SSCs were grown to confluence in 6-well plates, cryopreserved, and then thawed at a ratio of one cryopreserved well into a fresh 6-well plate (1:6). After three freeze-thaw cycles (roughly 3-4 weeks in culture and a 216-fold expansion, Figure 3A), primary SSCs grown in the xeno-free media formulation retained expression of the SSC markers GFRA1, CD90, and SSEA4 (Figure 3C-E).[43, 44] Over time, they also began to form grape-like clusters (Figure 3C), which is a morphology more typical of SSCs cultured on feeder cells.[45-48]

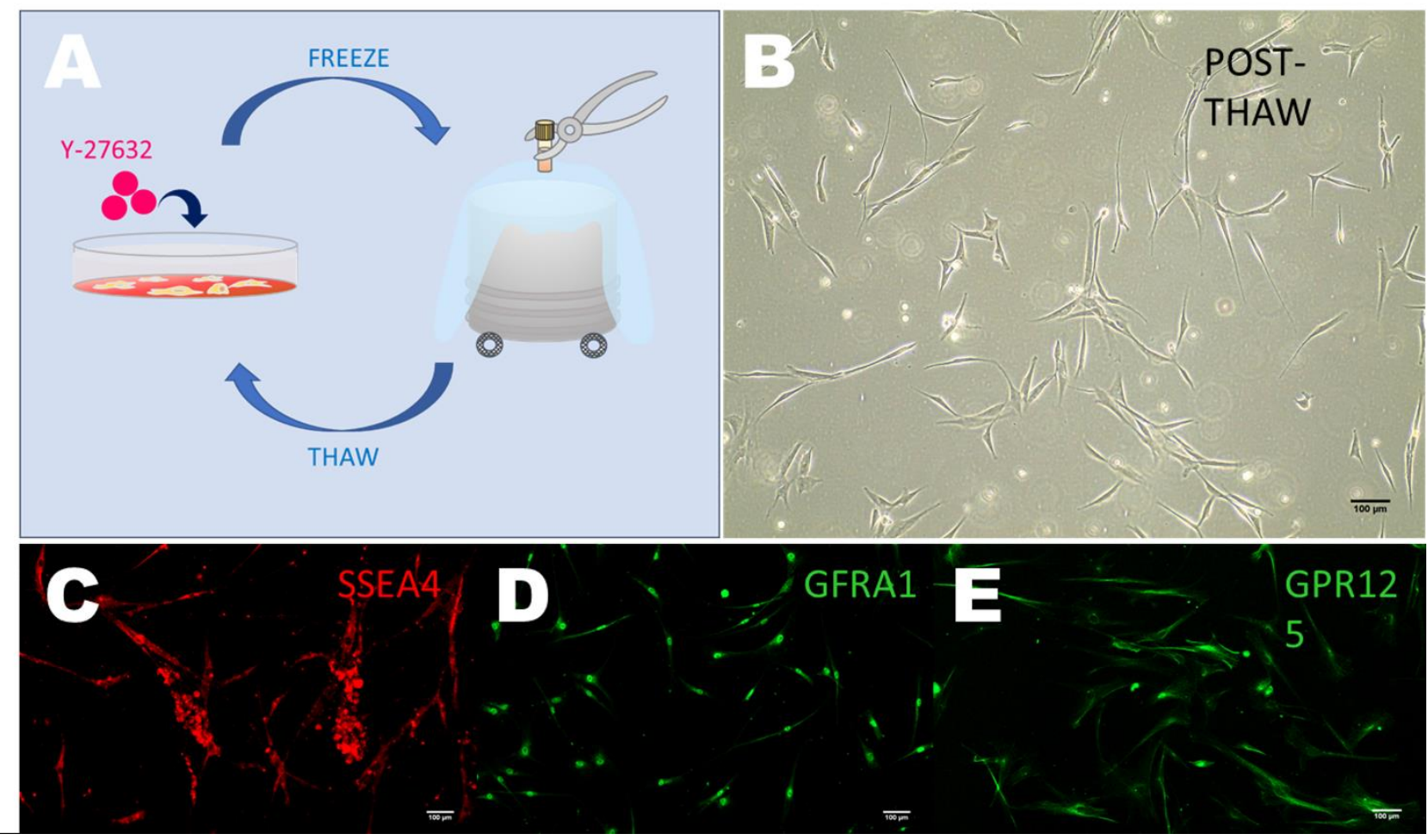

Figure 3: Long-term culture and characterization of primary SSCs in xeno-free conditions. A) Schematic representing long-term culture and freeze-thaw cycles before characterization: primary SSCs were 
expanded, frozen in liquid nitrogen, and then thawed with Y-27632 to promote viability, for a total of 3 cycles, or a 216-fold expansion. B) Microscope image of the primary SSCs 24 hours post-thaw in xeno-free conditions. C-E) Expression of the SSC markers SSEA4, GFRA1 and GPR125 after 216-fold expansion and 3 freeze-thaw cycles in xeno-free conditions. All scale bars are $100 \mu \mathrm{m}$. Abbreviations: SSC = spermatogonial stem cell, SSEA4 = Stage-Specific Embryonic Antigen-4, GFRA1 = GDNF Family Receptor Alpha 1, GPR125 = G Protein-Coupled Receptor 125 .

Gene analyses revealed no significant differences in gene expression between xeno-free and standard media for the quiescent SSC markers Inhibitor of DNA Binding 4 HLH Protein (ID4), and Fibroblast Growth Factor Receptor 3 (FGFR3),[43] however, the quiescent SSC marker Undifferentiated Embryonic Cell Transcription Factor 1 (UTF1)[43] was upregulated 5 \pm 1 -fold (Figure 4). The pan-germ cell marker DEAD-Box Helicase 4 (DDX4)[49] and was upregulated $7 \pm 1$-fold (Figure 4), and Deleted in Azoospermia Like (DAZL), a broad translational regulator of genes associated with SSC proliferation, differentiation and survival,[43, 50] was likewise increased 12 \pm 1 -fold (Figure 4). 


\section{Gene expression of SSCs in xeno-free conditions}

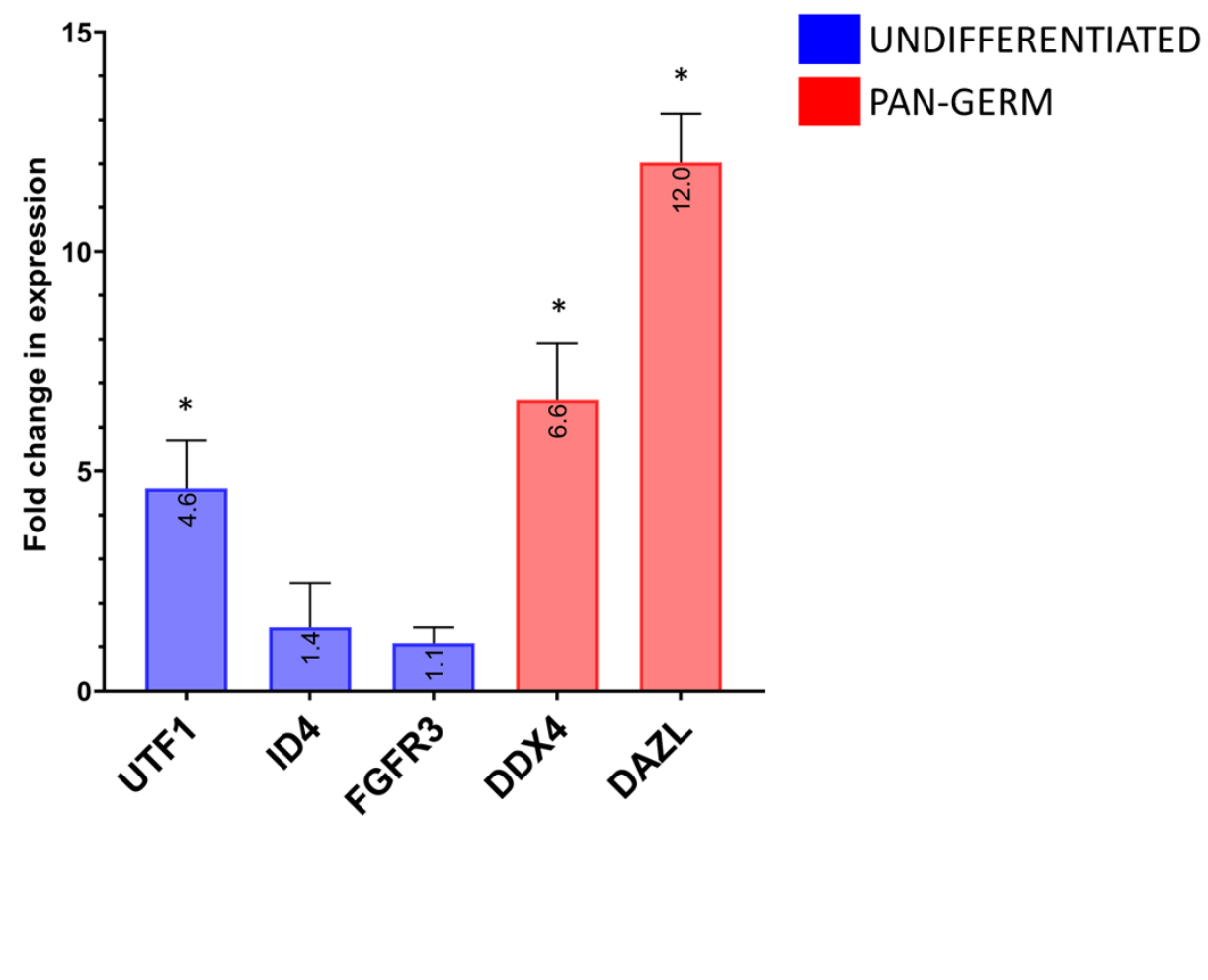

Figure 4: Gene expression of the long-term SSC cultures in xeno-free media compared to standard media. UTF1, ID4 and FGFR3 are quiescent SSC markers. DDX4 and DAZL are expressed by all germ cells. *indicates a statistically significant difference compared to the standard media. Abbreviations: SSC = spermatogonial stem cell, UTF1 = Undifferentiated Embryonic Cell Transcription Factor 1, ID4 = Inhibitor Of DNA Binding 4 HLH Protein, FGFR3 = Fibroblast Growth Factor Receptor 3, DDX4 = DEAD-Box Helicase 4, DAZL = Deleted in Azoospermia-Like.

\subsection{DISCUSSION}

We show that the animal components FBS and BSA in standard SSC expansion media can be replaced by the growth factors PGD-2 and IGF-1 without loss of viability or expansion capability 
for at least 3 passages and 3 freeze-thaw cycles. Moreover, the cellular morphology of these cells begins to resemble the characteristic grape-like clusters seen when SSCs are cultured on mouse embryonic feeder (MEF) cells,[33] or in mixed testicular cultures,[48] suggesting a more natural phenotype. SSC populations in xeno-free or standard media were otherwise confirmed to share identical protein expression by immunocytochemistry analysis for well-known SSC markers. RNA expression was noted to increase in quiescent SSC and pan-germ markers, indicating that the xenofree media was more supportive of SSC renewal than the standard media.

The most significant upregulation in gene expression was noted to be DAZL, a germ cell translational regulator that enhances gene expression by RNA binding and regulation of transcription factors and epigenetic regulators.[50, 51] It has a wide range of targets involved in processes from SSC proliferation and survival to differentiation. Observations in DAZL knockout mice suggest that one of its main functions is to enhance steady-state levels of SSC proliferation transcriptional regulatory factors,[51] suggesting that the xeno-free media promoted improved regulation of SSC proliferation.

There is currently one other reported xeno-free formulation for the expansion of SSCs,[52] however it relies on undefined human platelet lysate (hPL), which is a growth factor-rich alternative to FBS, collected from human platelets. While hPL is xeno-free, lot-to-lot variations are still a concern, as is the risk of pathogen contamination. $[53,54]$ Another limitation to the use of hPL is its ill-defined nature, since it introduces unknown factors to the cells, which can be detrimental to experimental design and analyses.

The effects of IGF-1 and PGD-2 on human germ cells are not well studied, however studies in mice suggest that IGF-1 acts in concert with GDNF and FGF-2 to promote complete cell cycle progression,[35] while PGD-2 supports gonocyte differentiation into SSCs and activates a 
quiescent state by repressing genes associated with the regulation of pluripotency, cell cycle arrest, and entry into meiosis.[36-38] Therefore, a possible explanation for their combined efficiency in promoting human SSC expansion is that together they regulate cell cycle progression while inhibiting pluripotency and pre-meiotic gene expression.

\subsection{CONCLUSIONS AND FUTURE DIRECTIONS}

This study shows that the growth factors PGD-2 and IGF-1 can replace the animal-derived components in established SSC expansion cell culture. This xeno-free, defined formulation can be used to standardize SSC in vitro culture, and removes the risk of pathogens and other unknown components.

Further investigation into the precise molecular mechanisms underlying the effectiveness of PDG2 and IGF-1 will help to better define and inform future culture practices. Additionally, experiments using xenotransplant models could assess the capability of xeno-free SSCs to colonize the testicular niche and differentiate.

\subsection{ACKNOWLEDGEMENTS}

The authors would like to acknowledge the Vancouver Prostate Centre for their funding support and our collaborators at the Willerth Lab at the University of Victoria and the Lange Lab at the Vancouver Prostate Centre for their generous assistance.

\subsection{FUNDING SOURCES}

This work was supported by the Vancouver Prostate Centre, a National Centre of Excellence, who provided access to shared equipment and software used for the collection and analyses of data, and start-up funding for new labs, but were not involved in the study design, report writing, interpretation of data, or in the decision to submit this study for publication. 
bioRxiv preprint doi: https://doi.org/10.1101/2021.06.04.447118; this version posted July 13, 2021. The copyright holder for this preprint (which

was not certified by peer review) is the author/funder, who has granted bioRxiv a license to display the preprint in perpetuity. It is made available under aCC-BY-ND 4.0 International license.

\subsection{DATA AVAILABILITY STATEMENT}

The data that support the findings of this study are available from the corresponding author upon reasonable request. 


\subsection{REFERENCES}

[1] E. Goossens, K. Jahnukainen, R.T. Mitchell, A. van Pelt, G. Pennings, N. Rives, J. Poels, C.

Wyns, S. Lane, K.A. Rodriguez-Wallberg, A. Rives, H. Valli-Pulaski, S. Steimer, S. Kliesch, A. Braye, M.M. Andres, J. Medrano, L. Ramos, S.G. Kristensen, C.Y. Andersen, R. Bjarnason, K.E. Orwig, N. Neuhaus, J.B. Stukenborg, Fertility preservation in boys: recent developments and new insights (dagger), Hum Reprod Open, 2020 (2020) hoaa016.

[2] J.M.D. Portela, C.M. de Winter-Korver, S.K.M. van Daalen, A. Meissner, A.A. de Melker, S. Repping, A.M.M. van Pelt, Assessment of fresh and cryopreserved testicular tissues from (pre)pubertal boys during organ culture as a strategy for in vitro spermatogenesis, Hum Reprod, 34 (2019) 2443-2455.

[3] V. Keros, K. Hultenby, B. Borgstrom, M. Fridstrom, K. Jahnukainen, O. Hovatta, Methods of cryopreservation of testicular tissue with viable spermatogonia in pre-pubertal boys undergoing gonadotoxic cancer treatment, Hum Reprod, 22 (2007) 1384-1395.

[4] A. Honaramooz, A. Snedaker, M. Boiani, H. Scholer, I. Dobrinski, S. Schlatt, Sperm from neonatal mammalian testes grafted in mice, Nature, 418 (2002) 778-781.

[5] M. Hou, M. Andersson, S. Eksborg, O. Soder, K. Jahnukainen, Xenotransplantation of testicular tissue into nude mice can be used for detecting leukemic cell contamination, Hum Reprod, 22 (2007) 1899-1906.

[6] H. Kaneko, K. Kikuchi, N.T. Men, M. Nakai, J. Noguchi, N. Kashiwazaki, J. Ito, Production of sperm from porcine fetal testicular tissue after cryopreservation and grafting into nude mice, Theriogenology, 91 (2017) 154-162.

[7] J. Yu, Z.M. Cai, H.J. Wan, F.T. Zhang, J. Ye, J.Z. Fang, Y.T. Gui, J.X. Ye, Development of neonatal mouse and fetal human testicular tissue as ectopic grafts in immunodeficient mice (vol 8, pg 393, 2006), Asian Journal of Andrology, 8 (2006) 583-583.

[8] M. Komeya, H. Kimura, H. Nakamura, T. Yokonishi, T. Sato, K. Kojima, K. Hayashi, K. Katagiri, H. Yamanaka, H. Sanjo, M. Yao, S. Kamimura, K. Inoue, N. Ogonuki, A. Ogura, T. Fujii, T. Ogawa, 
Long-term ex vivo maintenance of testis tissues producing fertile sperm in a microfluidic device, Sci Rep, 6 (2016) 21472.

[9] T. Sato, K. Katagiri, A. Gohbara, K. Inoue, N. Ogonuki, A. Ogura, Y. Kubota, T. Ogawa, In vitro production of functional sperm in cultured neonatal mouse testes, Nature, 471 (2011) 504-507.

[10] S. Sharma, J. Wistuba, T. Pock, S. Schlatt, N. Neuhaus, Spermatogonial stem cells: updates from specification to clinical relevance, Hum Reprod Update, 25 (2019) 275-297.

[11] K. Jahnukainen, J. Ehmcke, M. Nurmio, S. Schlatt, Autologous Ectopic Grafting of Cryopreserved Testicular Tissue Preserves the Fertility of Prepubescent Monkeys That Receive Sterilizing Cytotoxic Therapy, Cancer Res, 72 (2012) 5174-5178.

[12] C.M. Luetjens, J.B. Stukenborg, E. Nieschlag, M. Simoni, J. Wistuba, Complete spermatogenesis in orthotopic but not in ectopic transplants of autologously grafted marmoset testicular tissue, Endocrinology, 149 (2008) 1736-1747.

[13] N.P. Zarandi, G. Galdon, S. Kogan, A. Atala, H. Sadri-Ardekani, Cryostorage of immature and mature human testis tissue to preserve spermatogonial stem cells (SSCs): a systematic review of current experiences toward clinical applications, Stem Cells Cloning, 11 (2018) 23-38. [14] H. Sadri-Ardekani, M.A. Akhondi, F. van der Veen, S. Repping, A.M. van Pelt, In vitro propagation of human prepubertal spermatogonial stem cells, JAMA, 305 (2011) 2416-2418.

[15] B. Nickkholgh, S.C. Mizrak, S.K. van Daalen, C.M. Korver, H. Sadri-Ardekani, S. Repping, A.M. van Pelt, Genetic and epigenetic stability of human spermatogonial stem cells during longterm culture, Fertil Steril, 102 (2014) 1700-1707 e1701.

[16] S. Schlatt, L. Foppiani, C. Rolf, G.F. Weinbauer, E. Nieschlag, Germ cell transplantation into X-irradiated monkey testes, Hum Reprod, 17 (2002) 55-62.

[17] B.P. Hermann, M. Sukhwani, F. Winkler, J.N. Pascarella, K.A. Peters, Y. Sheng, H. Valli, M. Rodriguez, M. Ezzelarab, G. Dargo, K. Peterson, K. Masterson, C. Ramsey, T. Ward, M. Lienesch, A. Volk, D.K. Cooper, A.W. Thomson, J.E. Kiss, M.C.T. Penedo, G.P. Schatten, S. 
Mitalipov, K.E. Orwig, Spermatogonial Stem Cell Transplantation into Rhesus Testes Regenerates Spermatogenesis Producing Functional Sperm, Cell Stem Cell, 11 (2012) 715-726. [18] H. Sadri-Ardekani, C.H. Homburg, T.M. van Capel, H. van den Berg, F. van der Veen, C.E. van der Schoot, A.M. van Pelt, S. Repping, Eliminating acute lymphoblastic leukemia cells from human testicular cell cultures: a pilot study, Fertil Steril, 101 (2014) 1072-1078 e1071.

[19] H. Sadri-Ardekani, A. Atala, Testicular tissue cryopreservation and spermatogonial stem cell transplantation to restore fertility: from bench to bedside, Stem Cell Res Ther, 5 (2014) 68.

[20] T. Yao, Y. Asayama, Animal-cell culture media: History, characteristics, and current issues, Reprod Med Biol, 16 (2017) 99-117.

[21] A. Oikonomopoulos, W.K. van Deen, A.R. Manansala, P.N. Lacey, T.A. Tomakili, A. Ziman, D.W. Hommes, Optimization of human mesenchymal stem cell manufacturing: the effects of animal/xeno-free media, Sci Rep, 5 (2015) 16570.

[22] M. Cimino, R.M. Goncalves, C.C. Barrias, M.C.L. Martins, Xeno-Free Strategies for Safe Human Mesenchymal Stem/Stromal Cell Expansion: Supplements and Coatings, Stem Cells Int, 2017 (2017) 6597815.

[23] D.T. Shih, T. Burnouf, Preparation, quality criteria, and properties of human blood platelet lysate supplements for ex vivo stem cell expansion, N Biotechnol, 32 (2015) 199-211.

[24] J.E. Piletz, J. Drivon, J. Eisenga, W. Buck, S. Yen, M. McLin, W. Meruvia, C. Amaral, K. Brue, Human Cells Grown With or Without Substitutes for Fetal Bovine Serum, Cell Med, 10 (2018) 2155179018755140.

[25] A. Heiskanen, T. Satomaa, S. Tiitinen, A. Laitinen, S. Mannelin, U. Impola, M. Mikkola, C. Olsson, H. Miller-Podraza, M. Blomqvist, A. Olonen, H. Salo, P. Lehenkari, T. Tuuri, T. Otonkoski, J. Natunen, J. Saarinen, J. Laine, N-glycolylneuraminic acid xenoantigen contamination of human embryonic and mesenchymal stem cells is substantially reversible, Stem Cells, 25 (2007) 197202. 
[26] A. Mackensen, R. Drager, M. Schlesier, R. Mertelsmann, A. Lindemann, Presence of IgE antibodies to bovine serum albumin in a patient developing anaphylaxis after vaccination with human peptide-pulsed dendritic cells, Cancer Immunol Immun, 49 (2000) 152-156.

[27] T.A. Selvaggi, R.E. Walker, T.A. Fleisher, Development of antibodies to fetal calf serum with arthus-like reactions in human immunodeficiency virus-infected patients given syngeneic lymphocyte infusions, Blood, 89 (1997) 776-779.

[28] J.L. Spees, C.A. Gregory, H. Singh, H.A. Tucker, A. Peister, P.J. Lynch, S.C. Hsu, J. Smith, D.J. Prockop, Internalized antigens must be removed to prepare hypoimmunogenic mesenchymal stem cells for cell and gene therapy, Mol Ther, 9 (2004) 747-756.

[29] H. Agata, N. Watanabe, Y. Ishii, N. Kubo, S. Ohshima, M. Yamazaki, A. Tojo, H. Kagami, Feasibility and efficacy of bone tissue engineering using human bone marrow stromal cells cultivated in serum-free conditions, Biochem Bioph Res Co, 382 (2009) 353-358.

[30] L.G. Chase, U. Lakshmipathy, L.A. Solchaga, M.S. Rao, M.C. Vemuri, A novel serum-free medium for the expansion of human mesenchymal stem cells, Stem Cell Res Ther, 1 (2010).

[31] L.G. Chase, S.F. Yang, V. Zachar, Z. Yang, U. Lakshmipathy, J. Bradford, S.E. Boucher, M.C. Vemuri, Development and Characterization of a Clinically Compliant Xeno-Free Culture Medium in Good Manufacturing Practice for Human Multipotent Mesenchymal Stem Cells, Stem Cell Transl Med, 1 (2012) 750-758.

[32] Anon, StemProTM-34 SFM (1X), in.

[33] M. Kanatsu-Shinohara, N. Ogonuki, K. Inoue, H. Miki, A. Ogura, S. Toyokuni, T. Shinohara, Long-term proliferation in culture and germline transmission of mouse male germline stem cells, Biol Reprod, 69 (2003) 612-616.

[34] H. Sadri-Ardekani, S.C. Mizrak, S.K. van Daalen, C.M. Korver, H.L. Roepers-Gajadien, M. Koruji, S. Hovingh, T.M. de Reijke, J.J. de la Rosette, F. van der Veen, D.G. de Rooij, S. Repping, A.M. van Pelt, Propagation of human spermatogonial stem cells in vitro, JAMA, 302 (2009) 21272134. 
[35] S. Wang, X. Wang, Y. Wu, C. Han, IGF-1R signaling is essential for the proliferation of cultured mouse spermatogonial stem cells by promoting the G2/M progression of the cell cycle, Stem Cells Dev, 24 (2015) 471-483.

[36] B. Moniot, S. Ujjan, J. Champagne, H. Hirai, K. Aritake, K. Nagata, E. Dubois, S. Nidelet, M.

Nakamura, Y. Urade, F. Poulat, B. Boizet-Bonhoure, Prostaglandin D2 acts through the Dp2 receptor to influence male germ cell differentiation in the foetal mouse testis, Development, 141 (2014) 3561-3571.

[37] M. Rossitto, S. Ujjan, F. Poulat, B. Boizet-Bonhoure, Multiple roles of the prostaglandin D2 signaling pathway in reproduction, Reproduction, 149 (2015) R49-58.

[38] S.A. Ujjan, Prostaglandin D2 (PGD2) signalling and male germ cell : differentiation in the mouse embryonic testis, in, Université Montpellier II - Sciences et Techniques du Languedoc, 2014.

[39] WiCell, iPS(Foreskin)-1, in, WiCell, 2021.

[40] Y.C. Zhao, S.C. Ye, D.L. Liang, P.X. Wang, J. Fu, Q. Ma, R.J. Kong, L.H. Shi, X.P. Gong, W. Chen, W.B. Ding, W.J. Yang, Z.J. Zhu, H.X. Chen, X.X. Sun, J. Zhu, Z. Li, Y. Wang, In Vitro Modeling of Human Germ Cell Development Using Pluripotent Stem Cells, Stem Cell Rep, 10 (2018) 509-523.

[41] H. Valli, M. Sukhwani, S.L. Dovey, K.A. Peters, J. Donohue, C.A. Castro, T.J. Chu, G.R. Marshall, K.E. Orwig, Fluorescence- and magnetic-activated cell sorting strategies to isolate and enrich human spermatogonial stem cells, Fertil Steril, 102 (2014) 566-U328.

[42] I. Kaganman, Throwing a ROCK inhibitor at a problem, Nat Methods, 4 (2007) 544-544.

[43] J. Guo, E.J. Grow, H. Mlcochova, G.J. Maher, C. Lindskog, X. Nie, Y. Guo, Y. Takei, J. Yun, L. Cai, R. Kim, D.T. Carrell, A. Goriely, J.M. Hotaling, B.R. Cairns, The adult human testis transcriptional cell atlas, Cell Res, 28 (2018) 1141-1157. 
[44] J.L. Wang, S. Yang, R.H. Tian, Z.J. Zhu, Y. Guo, Q.Q. Yuan, Z.P. He, Z. Li, [Isolation, culture, and identification of human spermatogonial stem cells], Zhonghua Nan Ke Xue, 21 (2015) 208213.

[45] H. Kubota, R.L. Brinster, Spermatogonial stem cells, Biology of Reproduction, 99 (2018) 52-

74.

[46] L.H. Dong, S.G. Kristensen, S. Hildorf, M. Gul, E. Clasen-Linde, J. Fedder, E.R. Hoffmann, D. Cortes, J. Thorup, C.Y. Andersen, Propagation of Spermatogonial Stem Cell-Like Cells From Infant Boys, Front Physiol, 10 (2019).

[47] M. Kanatsu-Shinohara, T. Shinohara, Spermatogonial Stem Cell Self-Renewal and Development, Annu Rev Cell Dev Bi, 29 (2013) 163-187.

[48] Y. Zheng, A. Thomas, C.M. Schmidt, C.T. Dann, Quantitative detection of human spermatogonia for optimization of spermatogonial stem cell culture, Hum Reprod, 29 (2014) 24972511.

[49] D.H. Castrillon, B.J. Quade, T.Y. Wang, C. Quigley, C.P. Crum, The human VASA gene is specifically expressed in the germ cell lineage, P Natl Acad Sci USA, 97 (2000) 9585-9590.

[50] H.X. Li, Z.Q. Liang, J. Yang, D. Wang, H.B. Wang, M.Y. Zhu, B.B. Geng, E.Y. Xu, DAZL is a master translational regulator of murine spermatogenesis, Natl Sci Rev, 6 (2019) 455-468.

[51] L.L. Zagore, T.J. Sweet, M.M. Hannigan, S.M. Weyn-Vanhentenryck, R. Jobava, M. Hatzoglou, C.L. Zhang, D.D. Licatalosi, DAZL Regulates Germ Cell Survival through a Network of PolyA-Proximal mRNA Interactions, Cell Rep, 25 (2018) 1225-+.

[52] L.H. Dong, M. Gul, S. Hildorf, S.E. Pors, S.G. Kristensen, E.R. Hoffmann, D. Cortes, J. Thorup, C.Y. Andersen, Xeno-Free Propagation of Spermatogonial Stem Cells from Infant Boys, Int J Mol Sci, 20 (2019).

[53] K. Bieback, B. Fernandez-Munoz, S. Pati, R. Schafer, Gaps in the knowledge of human platelet lysate as a cell culture supplement for cell therapy: a joint publication from the AABB and the International Society for Cell \& Gene Therapy, Cytotherapy, 21 (2019) 911-924. 
bioRxiv preprint doi: https://doi.org/10.1101/2021.06.04.447118; this version posted July 13, 2021. The copyright holder for this preprint (which

was not certified by peer review) is the author/funder, who has granted bioRxiv a license to display the preprint in perpetuity. It is made available under aCC-BY-ND 4.0 International license.

[54] T. Burnouf, L. Barro, O. Nebie, Y.W. Wu, H. Goubran, F. Knutson, J. Seghatchian, Viral safety of human platelet lysate for cell therapy and regenerative medicine: Moving forward, yes, but without forgetting the past, Transfus Apher Sci, 58 (2019). 